\title{
Analysis of "Five-internal-organ" Relationship in College English Writing from the Perspective of "Five-element Model"
}

\author{
Bulei Zuo \\ School of Foreign Languages, Soochow University, China
}

\begin{abstract}
In this paper, the five-element theory and traditional Chinese medicine (TCM) Five-viscera Theory will be applied into the field of College English Writing (CEW). The characteristics and properties of the Traditional Five Elements and the Five Internal Organs have been in analogy to the five main elements in CEW, including idea, semantic aspect, grammatical aspect, lexical aspect and cohesion, the relationship among which will be verified based on the Generating Cycle and Restraining Cycle that are internal driving forces functioning in Five-viscera System of Chinese Culture, before coming to a conclusion that a dialectical unity relationship reinforcing each other exists in the elements of CEW.
\end{abstract}

Index Terms-Five Elements, Five Internal Organs, College English Writing, mutual generating and mutual restraining

\section{INTRODUCTION}

Creating specific writing lesson for Chinese English learners is challenging and time consuming for English teachers, but it is definitely worth the effort. In my experience, teaching writing through the perspective of traditional TCM five-viscera theory does interest students. This article will suggest a motivating way to teach writing with perceptions of relationship of "Five Internal Organs" of College English Writing (CEW) base on the perspective of "Five-Element Model".

Can Wuxing, the traditional five-element theory be applied into the practice of English writing? The answer is YES. As we all know, in traditional Chinese medicine (TCM), the characteristics and properties of the Traditional Five Elements (Metal, Wood, Water, Fire, Earth) and the Five Internal Organs (Lung, Liver, Kidney, Heart and Spleen) have similar associations with the five elements in English writing: A) Grammatical Range \& Accuracy; B) Coherence \& Cohesion; C) Lexical Resource; D) Voice and Main Ideas; E) Task Response(meaning), the relationship among which will be verified based on the Generating Cycle and Restraining Cycle that are internal driving forces functioning in Five-viscera System of TCM. A conclusion will be made that a dialectical unity relationship reinforcing each other exists in the elements of English writing, and an effective output could take place if the five elements in English writing are considered sufficiently.

\section{LITERATURE REVIEW}

\section{A. Current Teaching Practice of English Writing}

In FL teaching of China, the development of writing skills has been emphasized in senior middle schools. Because of the complexities of writing, many teachers in university simply avoid the area, instead concentrating on reading and translation.

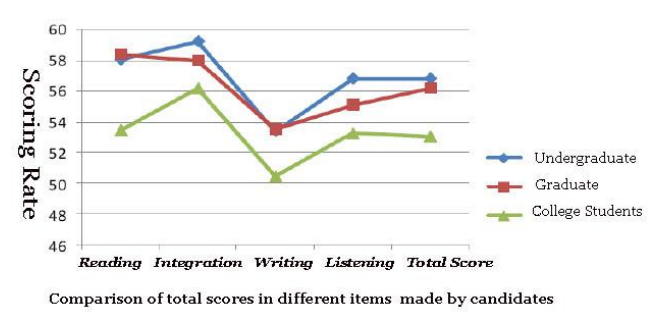

Writing is an effective way to communicate and express students' thoughts, feelings and opinions to others. English writing plays an important role in English teaching. As it is known to us all, written language is closely related to spoken language. It is impossible that a student who is poor in writing may be good at speaking, listening or reading. Learning English aims at using what we learned to write and speak. Remembering what we learned is only the first step. Additionally, writing, as one of the productive skills, should be viewed as ways and means to learn a foreign language. 
In recent years, the use of new teaching materials and the changes of items in the College Entrance Examination, marks of writing have been raised. So writing becomes relatively effectively means to exam students' comprehensive language proficiency

There is a consensus among many experts and scholars in China and abroad that writing is conductive to the improvement of English proficiency. The statistic of CET-4 writing samples from the second half year of 2012 shows that Chinese college students are the poorest in writing test compared with other item testing (see figure below, by Jin Yan, 2013)

Over observation, most Chinese college students have less sense of wholly structured arrangements. Some of them have no bright thesis statement, some have no clear task response, and some have grammatical errors. Actually, the instructions of writing task are clear and concise, which ensure that candidates have something to say, a purpose for saying it and audience in mind when they write. However, the result seems a bit bad.

\section{B. Five Viscera (zang-fu Organs) in TCM}

Creating specific writing lesson for Chinese English learners is challenging and time consuming for English teachers, but it is definitely worth the effort. In my experience, teaching writing through the perspective of traditional TCM five-viscera theory does interest students. It is beneficial to illustrate students the important relationship of "Five Internal Organs" of English Writing by analogy with the traditional Five-Element Theory,

TCM holds that human life is a physiological process in constant motion and change. The understanding of the human body is based on the holistic understanding of the universe as described in Daoism, and the TCM approach treats zang--fu organs as the core of the human body, which are connected through a network of channels and blood vessels inside human body. Diseases of body surface tissues may also affect their related zang or fu organs (visceras). Affected zang or fu organs may also influence each other through internal connections. TCM treatment starts with the analysis of the entire system, then focuses on the correction of pathological changes through readjusting the functions of the zang-fu organs: heart, liver, spleen, lung, and kidney. They are related to Five Elements in the nature: WOOD, FIRE, EARTH, METAL and WATER. As there are similar properties. TCM practitioners used to address them together and thought that there exists two circular cycle systems in human body. One cycle is called generating cycle: lung METAL producing kidney WATER, kidney WATER nourishing liver WOOD, liver WOOD feeding heart FIRE, heart FIRE resulting in spleen EARTH, spleen EARTH generating lung METAL. The other cycle is named as restraining cycle: lung METAL restraining liver WOOD, liver WOOD restraining spleen EARTH, spleen EARTH restraining kidney WATER, kidney WATER restraining heart FIRE, heart FIRE restraining lung META.

When applied to TCM, the theory of five elements is used to explain both physiological functions and pathological changes and guide clinical diagnosis and treatment according to the properties of the five elements and their generation, restriction, subjugation and counter-restriction relationships. Each of the internal organs, according to the theory of five elements, pertains to one of the five elements. For example, the liver prefers to grow freely and dislikes depression, so it pertains to wood; the heart pumps blood to warm the body, thereby it pertains to fire; the spleen is responsible for transforming and transporting cereal nutrients to all parts of the body, thus it pertains to earth; the lung is marked by the functions of purification and descending, for that reason it pertains to metal; the kidney is in charge of storing essence and governing water, therefore it pertains to water

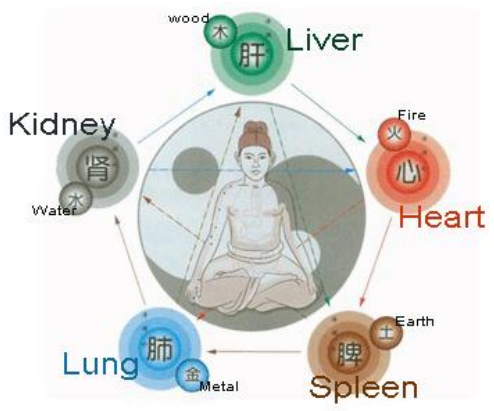

The properties of the five elements serve as an analogy to explain the physiological functions of the five zang-organs. The manifestations of the mutual promoting relationship among the five zang-organs can be generalized according to the motion order of the five elements.

The liver promoting the heart means wood generating fire, such as the liver storing blood to supplement the heart; the heart promoting the spleen means fire generating earth, such as heart yang warming the spleen; the spleen promoting the lung means earth generating metal, such as "the essence distributed by spleen qi flowing upward into the lung"; the lung promoting the kidney means metal generating water, such as downward flowing of pulmonary qi supplementing the kidney water; the kidney promoting the liver means water generating wood, such as the kidney storing essence to nourish blood in the liver; etc 


\section{ApPLication In EnGLish Writing}

\section{A. Yin and Yang in Writing}

As an ancient philosophical concept, the five elements of visceras works in an interactive and harmonious way. In language education, specially when teaching writing, the learners and the teacher could be called Yin and Yang, as Chinese ancient proverb says, one empty container and five chariots of knowledge. In addition, the teacher and teaching methods, the learners and their learning strategies, the textbook (teaching and learning material) and ideas inside, the language itself and culture included could be considered as yang and yin, because the pair of two opposites exists in one unity, mutually interactive, and participates in activities on a larger scale.

The use of the concept of yin-yang is a pragmatic one. It would be meaningful to say certain quality is yang and the opposite is yin, only if this designation classifies these two objects or qualities into two existing categories where many other things or qualities or attributes have already been classified. The truth is the learners and the teacher could be classified into Yang and Yin, if we emphasize on learning autonomy, like learners in strong motivation to learn and teacher in employment burnout.

A normal and ideal state in language education is that teacher functions as controller, director, manager, facilitator, and resource (H. Douglas Brown,1994), who interact and make two-way process of communication with classroom learners that have the willingness to listen, to experiment, to ask questions, to think about how to learn, to accept correction and to face up to making mistakes (Jeremy harmer ,1983), or classroom learners who have positive cognition, intrinsic motivation for meaningful learning, strategic investment of time, effort and attention , self-confidence, strong language ego(a second language identity), risk-taking to ask questions(H. Douglas Brown,1994), as interaction, the heart of communication, the collaborative exchange of thoughts, feelings, or ideas between or more people can result in a reciprocal effect on each other (Rivers, Wilga. 1987) put it this way: through interaction, students can increase their language store as they listen to or read authentic linguistic material, or even the output of their fellow students in discussions, skits, joint problem-solving tasks, or dialogue journals. To be exact, it is the interaction that produces Qi, a driving force existing in interacted discourse where learners and the teacher fulfill their objectives respectively for their roles being reversed. Just as what you see from the Figure 2, if teacher puts learners in her/his heart, and learners have teacher in their eyes, interaction between them would be possible. Meanwhile, when learning autonomy is increased, learners can be their own controller, director, manager or facilitator. There comes a state of unity, a dynamic equilibrium of educational functions, even in College English writing.

\section{B. Five Elements in Writing}

Here is a hypothesis: In College English writing, as a holistic view, there might be five elements similar to traditional Five Elements and Five Zang Organs, and the inner mechanism principle could be applied into College English Writing practice. Actually, there is the same attributes and characteristics?

Firstly, Each Chinese character is meaningful, even the constructing part of Chinese characters has specific meaning. The Chinese characters for "liver, spleen, lung, kidney" has a common side construct, named "moon (yue)", a visible container; the word "HEART (xin)" has no "moon" construct, invisible, immaterial, and in line with the characteristics of fire's being up forth coming. The WOOD, EARTH, METAL and WATER is under going or downward (Chen Junyu, 2012). Huangdi Neijing, also known as The Inner Canon of Huangdi or Yellow Emperor's Inner Canon, an ancient Chinese medical text mentions that HEART is the well-knit God governing mind and thoughts speaking out. In TCM, "God" orders the meridians to carry and distribute Qi and blood to all parts of the body, and connect the organs, limbs and joints. Therefore, in EFL, the heart should be the central idea of correspondence in English writing. As we know, when choosing a topic, we need to find ways to unlock the hidden ideas we have in our minds, , by brainstorming, free writing and looping techniques so as to generate ideas.

Secondly, the element of EARTH is the mother of all things, biochemical, nourishing all things. According to TCM, the organ spleen, is the source of Qi and blood, functioning as transporting water essence. Moreover, the spleen governs body muscles, with hidden nutrition. Similarly, the much semantic essence in meaningful context of EFL can be viewed as spleen. As we all now, after we explore our ideas, we need to put them into paragraph form, keeping in mind how showing and using facts and statistics makes writing powerful and convincing. The element of our intended meaning has to be conveyed to readers successfully. This step can be very fascinating adventure. By stepping out of our own selves and discover the impact of our words on the thoughts and eyes of our readers. Reediting and revising what we have created is a good way to make your meaning communicated effectively. Anyway, meaning is the mother of any compositions.

Thirdly, the corresponding viscera METAL element should be lung, which advocates fur, with vital Qi according to the Inner Canon of Huangdi (Hao Yi, 2011). In EFL, what is the fur of English writing? Surely the language message and grammatical rule are. Once we have made the necessary changes in your composition, we can rewrite it legibly, go over it carefully to see if the language sounds correct and the message seems complete and understandable. Most importantly, from the Chinese perspective, the message has to follow grammatical rules. In TCM, the lung governs air breathing, very consistent, and makes vital Qi moving smooth and forward until coming to a shape. Grammar is a system of rules governing the conventional arrangement and relationship of words in a sentence. Actually, the components of words (prefixes, suffixes, roots, verb and noun endings, etc.) are indeed a part of grammar. Here we not 
only refer to sentence-level rules, but also the discourse rules which governing the relationship among sentences. Only all these grammatical form are correct, a good writing might be created, as the main function of grammar works as "breathing smoothly" (Liu Lihong, 2006).

In TCM, skeleton and bone belong to Kidney WATER, governing the flow of vital Qi and bones. In EFL, the element WATER seems like the piles and piles of words and phrases. In China, grammar was the major center of attention in language classes few decades ago. Nowadays vocabulary has become the focus of drills, exercises and memorization efforts. The semantic expression in English writing requires combined words and expressions to certain extend. Correspondingly, lexicon should make sense if compared to WATER, which is flowing and flexible and nutrition in feeding a discourse.

The final element WOOD is characterized by uprising, thriving, flourishing, generating, stretching, smoothing, literally springing forth of growth after long period of hibernation. WOOD, especially in spring, like the start of new life cycle, is associated with vigor, youth, and growth. It in energy is creative and expands up forward freely. In EFL writing class, what can be called WOOD is surely the linking words, which associates sentences, semantic forms and words. Based on the Inner Canon of Huangdi, liver WOOD belongs to Yin meridian, rather than meridian, so it should not classified as the surface of matter, but the hidden meridian. Coherence, as a hidden rule governing fluency and appropriate (Harmer J. 2000) is surely in analogy to WOOD.

\section{The Dialectical Relationship}

As a dialectical relationship exists in the five internal organs, there are some similar relationship among the such five writing elements as A) Grammatical Range \& Accuracy; B) Coherence \& Cohesion; C) Lexical Resource; D) Voice and Main Ideas; E) Task Response (meaning). The five aspects are corresponding with the minimum criteria proposed by Heaton (1988:146): language use; mechanics, Vocabulary; content; and organizations. They are also equal to the five elements claimed by Weir (1993:136): Grammar; Cohesion; adequacy of vocabulary for purpose; Appropriateness of language and layout; Content and organization. All these elements support the a good composition.

\begin{tabular}{|c|c|}
\hline Weir 1993: 136 & Heaton 1995: 146 \\
\hline $\begin{array}{l}\text { Relevance and adequacy of } \\
\text { content } \\
\text { Organization } \\
\text { " Cohesion } \\
\text { Adequacy of vocabulary for } \\
\text { purpose } \\
\text { Grammar } \\
\text { : Punctuation } \\
\text { Spelling } \\
\text { Appropriateness of language } \\
\text { to context, function and } \\
\text { intention } \\
\text { Appropriateness of layout }\end{array}$ & $\begin{array}{l}\text { Content } \\
\text { Organization } \\
\text {, Vocabulary (vocabulary range, } \\
\text { idiomatic use of vocabulary) } \\
\text { Language use (complexity of } \\
\text { construetions) } \\
\text { Mechanics (spelling, } \\
\text { punctuation, writing } \\
\text { conventions, capitalization, } \\
\text { paragraphing etc.) }\end{array}$ \\
\hline
\end{tabular}

As to the generating cycle, the writer should have the view point or main ideas (Fire) first in her/is mind before expressing the meanings or messages clearly and directly, followed by appropriate structure where task responses can be reflected in each paragraph. Each passage should have correct grammatical form, varied, and accurate ranges. Coming to the next is the proper word choice and coherent writing text, which communicates the writer's voice about his thoughts, values or spirit. Just as the Inner Canon of Huangdi goes like that "the mortal body, is supported by bone-based stem, reinforced by a beam of the joints, piped by veins and meridians with flesh and skin surrounded here and there. Similarly, the five writing elements have the same functions which vocabulary and bones as skeleton, cohesion, coherence as the joints, and main ideas included in the context, where meaningful construction and grammatical form attached to the lexical chunks and items.

As for the Restraining Circle, accuracy featured by correct grammar usage affects the expression of cohesion and coherence. Less coherence restrains the output of meaning, which is more superior than fancy words. Word choice limits the effective and influent expression of points of view, which, in turn, has limited the vast usage of grammatical forms, as shown in figure 3.

This model can be seen in writing sentences, where cohesion and sentence structure are needed. Among the cohesive forms, lexical cohesion was the most prevalent. The use of lexical cohesion instead of other cohesive devices seems to be associated with the lexical resource and main idea. That is, lexical cohesion, by repeating words or phrases, seemed preferred for indicating textual relationships, rather than using substitution or reference. For example, a business English problem would be written in the following way:

John bought a shirt on sale for $50 \%$ off the original price. If the shirt originally cost $\$ 25$, what was the final sale price that John paid for the shirt? (Italics indicate lexical cohesion.) 


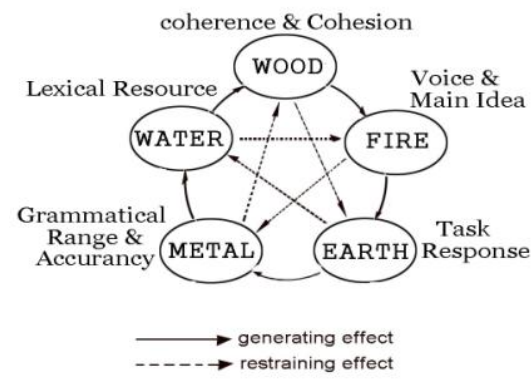

Five Elements in English Writing

Notice in the example, the appropriate references such as "he" for John or "it" for shirt were not used. With respect to sentence structure, simple sentences were dominant, although some complex sentences were observed. It was interesting to note that the use of more complex sentence structures was subject to grammatical range and task response.

\section{ANALYSIS OF SAMPLE WRITING}

The below-mentioned sample writing is made by one of my college students who drafted the essay titled Love and Infatuation in FROZEN, after watching a cartoon movie FROZEN, which was American 3D computer-animated musical fantasy-comedy film produced by Walt Disney Animation Studios and released by Walt Disney Pictures.

There are two types of emotional sense: true love and infatuation. True love is a lasting long feeling, likely to include a process of "growing" in love, which cares about the loved person's merits and shortcomings, while infatuation is a sudden "falling" in love, which mainly concerns about one's own needs and satisfaction.

Prince Hans from Southern Isles attended Elsa's coronation Ceremony and fell in love with Princess Anna of Arendelle at the first sight. The young couple promised to marry each other. The end of the story told us that Hans was crazy about marrying into a throne of Kingdom Arendelle rather than the "loved" princess, as he had no chance to stand among his thirteen princes. It is evident that the short term feeling of relationship Princes Hans had towards Anna is infatuation instead of true love because true love is devoted to making the other person happy, while infatuation leads a person to a feeling of insecurity and no trust.

However, Kristoff, an ordinary Ice hunter from North Mountain could offer a hand to Anna when she was in trouble. He tolerated Anna's good and bad, and the concern for Anna developed naturally. When Kristoff knew that Anna might be drowned in danger, he returned to save Anna without hesitation. Obviously, Anna and Kristoff were able to get through their problems together, which showed that the feeling of true love meant to have one another in the eyes and take care of it forever.

A belief that the other person is beautiful is an important part of both infatuation and love, but a surface attraction is less important in true love. The couple in true love will usually build their relation on a broader base than just being drawn to a pretty face. True love involves a measure of belief in yourself and a degree of self-respect, a desire to sacrifice himself for your loved one, so that one may accept, respect and trust another person.

To make comments, i would like to say that this is a great essay, the main idea, language task, grammar, word choice, coherence, structure of paragraphs and sentences, are interacted, showing high level of English. Meanwhile, the comparison and contrast are clearly enlightened up.

Here is another simple writing of CET-4

Recently, museums in mounting numbers become admission-free to the public both home and abroad. The purpose of this practice is to offer more opportunities for citizens to explore and get easy access to the world of history, culture and knowledge.

Although free admission to museums enjoys distinct advantages, it also brings harmful effects. In the first place, these valuable cultural relics displayed may be damaged or destroyed consciously or unconsciously by the crowds. In the second place, it becomes a huge economic burden for museums to run as usual without any profits from the visitors.

It is my view that free admission to museums is of utmost significance. For one thing, we should appeal to our authorities to legislate strict laws and regulations to protect these museums. For another, we should cultivate the awareness of people that museums are extremely vital to us humans. It is high time that we attached great importance to our motherlands' splendid and glorious culture of more than five thousand years

Obviously, this composition shows strict arrangements of ideas. The main viewpoint is "Free admission to museums is of utmost significance". At opening sentence, the author states the purpose of taking free admission to museums, like offering more opportunities for citizens to explore, getting easy access to the world of history, culture and knowledge. and in the closing sentences, the author clarifies two actions, which echoes the opening sentences. It is the coherence and cohesion that generate proper main ideas (proper action to be taken can offset or inhibit the harmful effects caused by free admission to museums), which are supported by correct word selection and grammar correction. 


\section{SUMMARY}

This analysis of Chinese Traditional Five-Element Theory applied in EFL or ESL where English writing is often taught, is just an attempt to explore the overall relationship among all element of writing. As a matter of fact, should all elements be carefully considered, an excellent article would be produced naturally, even thought some hypothetical classifications of elements and relationships tend to be valuable for future empirical test. As a specific perspective of teacher's action research, it is necessary to consider the dynamic balance among all elements and find the right ways to deal with the troubling teaching issues. Anyway, this research opens up new paths for dynamic and effective classroom writing tips in EFL field.

\section{ACKNOWLEDGMENT}

Financially support by the Provincial Philosophy and Social Science Foundation of Jiangsu, China (Grant NO. 2013SJB740032) and the Fundamental Research Funds for Soochow University (Grant NO. 5731501213).

\section{REFERENCES}

[1] Chen Junyu. (2012). Using Five Elements Theory to analyze the relationship of writing Elements. Times Literature, 4:106-107.

[2] Hao Yi. (Ed). (2011). The Inner Canon of Huangdi. Beijing: Zhonghua Book Company.

[3] H. Douglas Brown. (1994). Teaching by Principles; An Interactive Approach to Language Pedagogy. Prentice Hall Regents.

[4] Harmer J. (1983). The Practice of English Language Teaching. London: Longman Group Ltd.

[5] Harmer J. (2000). How to Teach English. Beijing: Foreign Language Teaching and Research Press.

[6] Heaton, J.B. (1988). Writing English language tests. Longman, New York.

[7] Liu Lihong. (2006). Thinking of TCM. Guilin: Guangxi Normal University press.

[8] Rivers, Wilga M. (Ed.).(1987). Interactive Language Teaching. Cambridge: Cambridge University Press.

[9] Zuo Bulei. (2013). Elements of Foreign Language Teaching. Guangzhou: World publication Company.

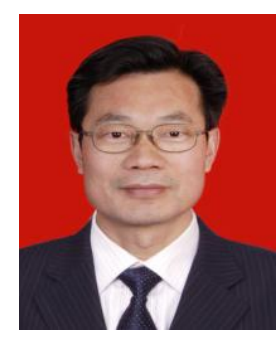

Bulei Zuo was born in Huai'an, China in 1965. He received his Master's degree in linguistics from Northeast Normal University, China in 2005. He is currently an associate professor in the School of Foreign Languages, Soochow University, Suzhou, China. His research interests include applied linguistics and English education. 